\title{
LUPEOL VALIDATION AND QUANTIFICATION IN HETEROPOGON CONTORTUS (L.) BEAUV. (SPEAR GRASS) THROUGH HIGH-PERFORMANCE THIN-LAYER CHROMATOGRAPHY
}

\author{
NAVJOT KAUR*, RAGHBIR CHAND GUPTA \\ Department of Botany, Punjabi University, Patiala, Punjab, India. Email: navjot21188@gmail.com
}

Received: 18 July 2017, Revised and Accepted: 05 October 2017

\begin{abstract}
Objective: This is aimed to study the chromatographic evaluation of triterpenoid, i.e., lupeol from methanolic extracts of leaves, stem, and inflorescence of Heteropogon contortus.

Methods: The high-performance thin-layer chromatography (HPTLC) densitometry determination of lupeol was performed using optimized mobile phase toluene:methanol:formic acid (7:3:0.3 v/v) with a derivatization of freshly prepared anisaldehyde-sulfuric acid. For densitometry measurements, the plates were scanned at $530 \mathrm{~nm}$ absorbance/reflectance wavelength. Quantification of lupeol marker compound in $H$. contortus leaves, stem, and inflorescence is estimated using $2-12 \mu \mathrm{g} / \mathrm{spot}$.
\end{abstract}

Results: The appearance of light purple bands on the chromatograms confirmed the lupeol component in plant samples. Further, the confirmation of the compound is done from the densitometric scanning by comparing $\lambda_{\max }$ values. From this, it is reported that lupeol is present in leaf samples, i.e., $10 \mathrm{mg} / \mathrm{g}$ of dry wt., while in rest of the two samples, it is found absent.

Conclusion: The leaves of $H$. contortus (spear grass) are a good source of lupeol and can be used as an alternate natural source to synthesize herbal drugs to control cancer and other anti-inflammatory agents. The presently selected HPTLC is validated and most accurate for the quantification and identification of lupeol present in the selected plant. The leaves of the species which are rich in lupeol can be used in pharmaceutical industry.

Keywords: Lupeol, High-performance thin-layer chromatographic, Triterpenoid, Heteropogon contortus.

(C) 2017 The Authors. Published by Innovare Academic Sciences Pvt Ltd. This is an open access article under the CC BY license (http://creativecommons. org/licenses/by/4. 0/) DOI: http://dx.doi.org/10.22159/ajpcr.2017.v10i12.21431

\section{INTRODUCTION}

Triterpenoids are the secondary metabolites and have great importance in medicinal plants [1]. These are derived from vegetable oils, cereals, fruits, and vegetables and are consumed at an average of $250 \mu \mathrm{g} /$ day [2]. Lupeol is an active triterpenoid. It exhibits important biological activities such as antiprotozoal, antitumor (antiprostate cancer, anti-melanoma, anti-head and neck squamous cell carcinoma, and anti-pancreatic cancer) [3-5], nutraceutical or chemopreventive agent [6-8], anti-inflammatory [9], and hepatoprotective [10].

Heteropogon contortus (L.) Beauv. (= Andropogon contortus L.), belonging to the family Poaceae (Gramineae), is commonly known as spear grass, black spear grass, bellary grass, kher (Hindi), gantegawata (Marathi). It is distributed in Southern Asia, Southern Africa, and Northern Australia. According to Blake and Richards [11], the grass is reported to have myo-inositol, galactinol, and raffinose. Polysaccharides were also observed in the plant species. It is medicinally important grass and is found useful in toothache, fever, atrophy, emaciation or cahexy, muscular pain, hematological disorders, dysentery, and scorpion sting $[12,13]$. Roots have diuretic and stimulant properties. The whole plant is used for asthma in the form of extracts or steam distillation product [14]. Oil distilled from the awns has been found to be useful in asthma.

Previously, Ghante et al. [15] obtained the results from the methanolic extract of $H$. contortus that it is used for the treatment of pathologies caused by mast cell destabilization, membrane destabilization, and free radical generation, which mainly include acute and chronic inflammatory response such as asthma, arthritis, cardiovascular, and neural diseases. Further, it was reported that $H$. contortus extract inhibits bronchoconstriction induced by histamine or acetylcholine [16]. Grasses are very important both economically as well as medicinally from the ancient time of herbal medicine use [17]. Compared the antimicrobial activities of ethanolic and hydroalcoholic extract of Vetiveria zizanioides root (a grass) and analyze the major bioactive compounds present in those extracts through high-performance thin-layer chromatography (HPTLC). It also inhibits inflammation induced by carrageenan and egg albumin. Some medicinally important grasses also show cytomorphological variations such as meiotic abnormalities and reduced pollen fertility [18]. Extraction-based studies were made on Ormocarpum cochinchinense and resulted that phenols in acetone and terpenoids in methanol extracts give better results for phytochemical analysis [19]. Thus, during the present study, methanol is used as a solvent for the quantification of lupeol from leaves, stem, and inflorescence of $H$. contortus.

\section{METHODS}

\section{Standard markers and chemical compounds}

Reference standard, i.e., lupeol was purchased from Himedia. Chemicals such as toulene, formic acid, and methanol were obtained from S.D. Fine Chemicals, Mumbai, India. Pre-coated silica gel $60 \mathrm{~F}_{254}$ HPTLC aluminum plates $\left(20 \times 20 \mathrm{~cm}^{2}\right.$ layer thickness-0.2 mm, 5-6 $\mu \mathrm{m}$ particle size; E. Merck, Darmstadt, Germany) was obtained from E. Merck Ltd. (Mumbai, India).

\section{Collection of plant material and sample preparation}

The material for the present study was collected from different localities of Udaipur district of Rajasthan, India. The plant is authenticated from Botanical Survey of India, Arid Zone Regional Center, Jodhpur, Rajasthan. The leaves, stem, and inflorescence (with awns) were excised from the plant. The collected material is then washed under running tap water, air-dried, and grinded to form a fine powder. $5 \mathrm{~g}$ dried powder of each plant part was extracted with 150 $\mathrm{ml}$ methanol using Soxhlet extractor for $8 \mathrm{hrs}$. The obtained extracts 
were then filtered and concentrated using rotary vacuum evaporator and then lyophilized with Allied Frost Lyophilizer-FD-3. The obtained lyophilized powder of samples was accurately weighed and then dissolved in methanol $(1 \mathrm{mg} / 1 \mathrm{ml})$. These solutions were then used as test solutions for HPTLC analysis.

\section{Equipment}

- Spotting device-CAMAG Linomat V sample applicator (CAMAG, Switzerland)

- $\quad$ Syringe- $100 \mu$ l Hamilton syringe

- TLC Chamber-CAMAG twin trough chamber.

- Scanner-CAMAG TLC scanner with $\mathrm{D}_{2}$ and Hg lamp, Reprostar and win CATS planar chromatography manager and CAMAG integration software and TLC viewing cabinet (all from CAMAG, Muttenz, Switzerland)

\section{Preparation of standard stock solution}

Accurately weighed reference standard lupeol ( $5 \mathrm{mg}$ ) was transferred to $10 \mathrm{ml}$ volumetric flask, dissolved in $5 \mathrm{ml}$ methanol $(1 \mathrm{mg} / 1 \mathrm{ml})$. The stock solution was ready to use for HPTLC.

\section{Chromatographic analysis}

The HPTLC analysis was performed using precoated silica gel $60 \mathrm{~F}_{254}$ aluminum plates. Linomat $\mathrm{V}$ autosampler was used for spotting of standard lupeol $(2,4,6,8,10$, and $12 \mu \mathrm{l}$ each) and sample solutions (10 $\mu \mathrm{l}$ each) operated with $6 \mathrm{~mm}$ band length, distance between the tracks $10 \mathrm{~mm}$, distance from the bottom of the plate, $8.0 \mathrm{~mm}$. The linear ascending developments were carried out up to a distance of $75 \mathrm{~mm}$ in a CAMAG twin trough chamber presaturated with mobile phase toluene:methanol:formic acid (7:3:0.3 v/v) for 25 minutes, and anisaldehyde is used as derivatizing reagent. The plates were then scanned in the CAMAG TLC scanner V, operated by win CATS software in the absorbance mode at $530 \mathrm{~nm}$. The images of the plates were then taken in the visible mode.

\section{Calibration curve of lupeol}

The standard stock solutions ( $1 \mathrm{mg} / 1 \mathrm{ml}$ ) of lupeol (2-10 $\left.\mu \mathrm{g} \mathrm{spot}^{-1}\right)$ were applied in triplicate on an HPTLC plate. These plates were developed with the mobile phase toluene:methanol:formic acid (7:3:0.3 v/v) for 25 minutes. After development, the plates were air-dried and scanned at $530 \mathrm{~nm}$ absorbance using deuterium lamp. The resolved peak areas were recorded for all the standards separately. The calibration curve of lupeol was plotted by taking peak area versus concentrations of standards (Fig. 1).

\section{Method validation}

The HPTLC method was validated using the ICH guidelines for specificity, linearity, limits of detection and quantification, precision and accuracy, robustness, and stability [20].

\section{Specificity}

The specificity was revealed by analyzing the standard marker compound and plant samples. The band of lupeol was confirmed by

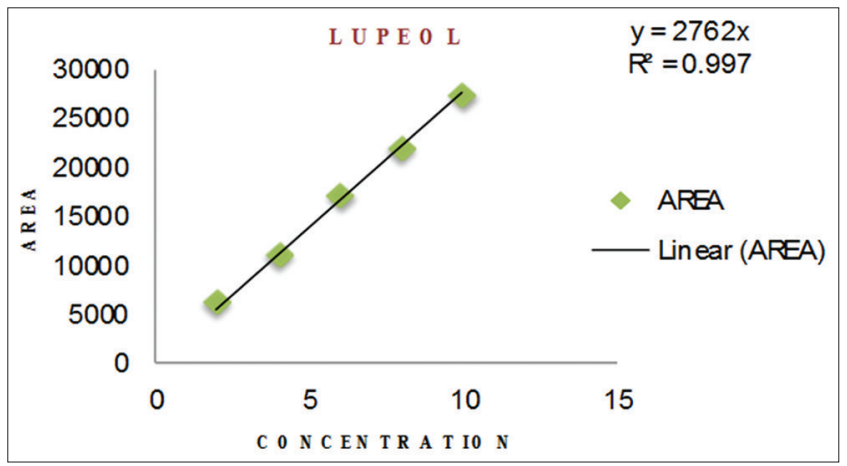

Fig. 1: Calibration curve of lupeol comparing the $\mathrm{R}_{\mathrm{f}}$ and ultraviolet (UV) spectra of the spots to those of the standard.

\section{Linearity}

The different concentrations $\left(2,4,6,8,10\right.$, and $\left.12 \mathrm{ng} \mathrm{spot}^{-1}\right)$ of lupeol were applied on the HPTLC plate in triplicates, separately. The plate was developed as prescribed above. The calibration curve was drawn by plotting the standard concentrations ranges from 2 to $12 \mu \mathrm{g} \mathrm{spot}^{-1}$ versus peak area. The linear calibration curve was obtained from which linear regression equation and correlation coefficients were obtained.

Limit of detection (LOD) and limit of quantification (LOQ)

The LOD and LOQ for the present marker compound, i.e., lupeol was calculated using the following equations:

$\mathrm{LOD}=3.3 \mathrm{SD} / \mathrm{S}$

$\mathrm{LOQ}=10 \mathrm{SD} / \mathrm{S}$

Where SD stands for the standard deviation of replicates under the same conditions, and $\mathrm{S}$ is the slope of the calibration curve.

\section{Robustness}

Robustness was studied in triplicate at $800 \mathrm{ng} \mathrm{spot}^{-1}$ by making small changes to the volume of the mobile phase, the composition of the mobile phase, and saturation time of development chamber. The effects on the results were examined by calculation of relative SD (RSD) (\%) and $R_{\mathrm{f}}$ values.

\section{Precision and accuracy}

Instrumental precision was checked by repeated scanning $(n=6)$ of same spot for each standard separately $\left(10 \mu \mathrm{g} \mathrm{spot}^{-1}\right)$ and expressed as \% RSD. The accuracy of the present method was checked using a recovery study by spiking the sample with two levels of standards ( 6 and $12 \mu$ band $^{-1}$ ). The $\%$ recovery was calculated using the formula given by the [21].

\section{Quantitative determination of lupeol}

The samples prepared from leaves, stem, and inflorescence of H. contortus were analyzed by using the validated HPTLC method, and the amount of the referred standard was calculated from the standard calibration curve of lupeol.

\section{RESULTS AND DISCUSSION}

During the present investigation, chromatographic conditions were optimized for the detection of lupeol using modified mobile phase toluene:methanol:formic acid $(7: 3: 0.3 \mathrm{v} / \mathrm{v})$ which gave the better

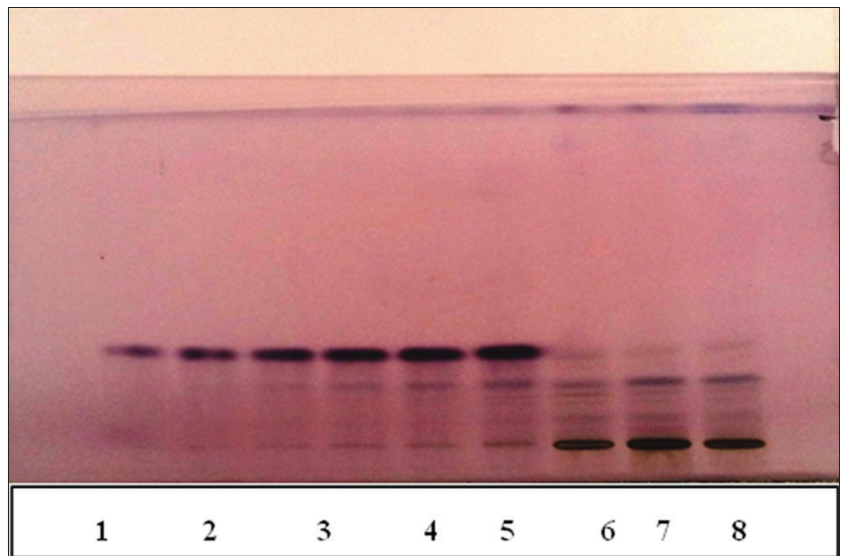

Fig. 2: High-performance thin-layer chromatography profile of lupeol (track 1-6) and methanolic plant samples of Heteropogon contortus (racks 7-9); 7(HCLM), 8(HCSM), 9(HCIM) 
results, i.e., sharp and well-resolved bands of lupeol at $R_{f}$ value of 0.21 (Fig. 2). Besides, the plates were derivatized with freshly prepared anisaldehyde-sulfuric acid and were heated at $110-120^{\circ} \mathrm{C}$ and scanned for densitometry measurements at an absorbing wavelength of $530 \mathrm{~nm}$ (Fig. 3). The identity and purity of the bands of selected sterols resolved in the plant samples (leaves, stem, and inflorescence)

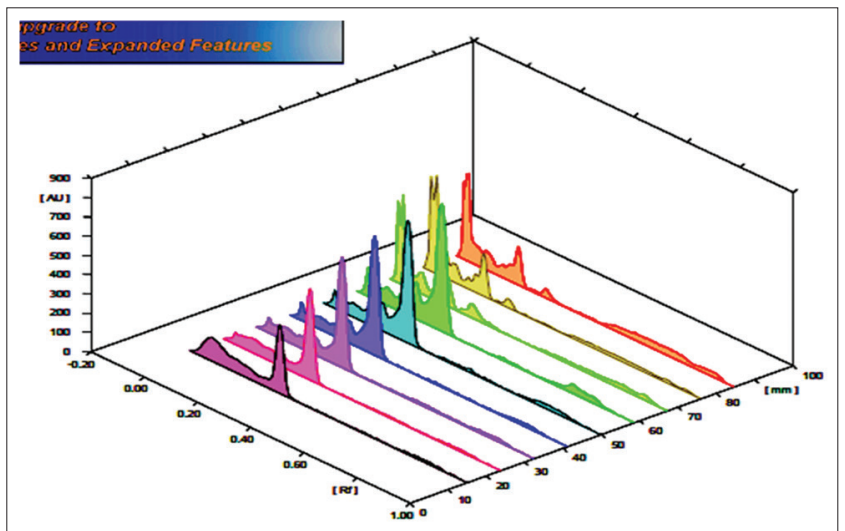

Fig. 3: Densitometric chromatogram of lupeol (track A-F); and plant samples of Heteropogon contortus (track G-I) HCLM, HCSM, and HCIM $\left(\lambda_{\text {max }} 520 \mathrm{~nm}\right)$ (three-dimensional view)

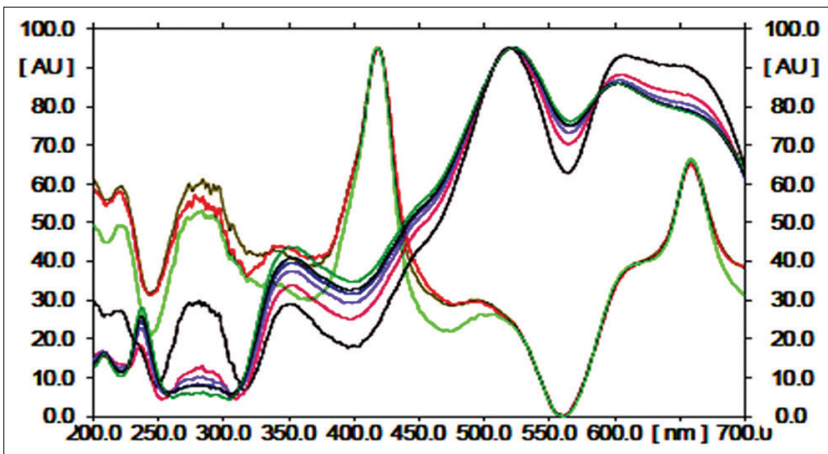

Fig 4: Absorption spectra of lupeol and plant samples of H. contortus (HCLM, HCSM, HCIM)

Table 1: Method validation parameters for the simultaneous quantification of lupeol

\begin{tabular}{ll}
\hline Parameters & Lupeol \\
\hline Wavelength $(\mathrm{nm})$ & 530 \\
$\mathrm{R}_{\mathrm{f}}$ & 0.28 \\
Selectivity & Selective \\
Specificity & Specific \\
Linearity range $(\mu \mathrm{g} / \mathrm{spot})$ & $2-12$ \\
Correlation coefficient $\left(\mathrm{R}^{2}\right)$ & 0.997 \\
Linear regression equation $(\mathrm{y})$ & $2762 \times$ \\
LOD (ng spot $\left.{ }^{-1}\right)$ & 0.84 \\
LOQ (ng spot & -1 ) \\
Accuracy (average \% recovery) & 0.25 \\
\hline
\end{tabular}

LOD: Limit of detection, LOQ: Limit of quantification were confirmed by overlaying their UV-visible absorption spectra with those of the standard compound using TLC scanner V (Fig. 4). Line-to-line overlay spectra of leaf sample were obtained which shows that the identity and purity of the bands matches with those of the standard compound while stem and inflorescence show little bit variation in $\lambda_{\text {max }}$. It shows that lupeol is absent in leaf and inflorescence of $H$. contortus.

The method is validated as per the ICH guidelines in terms of precision, repeatability, and accuracy (Table 1 ). The linearity range for lupeol was found to be $2-12 \mu \mathrm{g} \mathrm{spot}^{-1}$ with correlation coefficient, i.e., 0.997. A linear calibration curve was obtained for the standard compound as described above. LOD value for a standard compound is $0.84 \mathrm{ng} \mathrm{spot}{ }^{-1}$, whereas LOQ value is $0.25 \mathrm{ng} \mathrm{spot}^{-1}$. The average $\%$ recovery at 3 different levels of the referred marker compound was found to be 99.45 (Table 1). The accuracy of the present method was determined by spiking the sample along with known amounts of standard $\left(100 \mu \mathrm{g}_{\text {band }}{ }^{-1}\right)$. The present method showed a recovery of $99.05 \%$ for the addition of $100 \mu \mathrm{g} \mathrm{band}^{-1}$ of standard correspondingly (Table 2).

The results of quantification of lupeol are given in Table 3. During the present investigation, lupeol is only detected in leaf samples, whereas in rest of the two samples, i.e., stem and inflorescence, it is found to be absent. The amount of lupeol present in the leaf sample is $10 \pm 0.13 \mathrm{mg} / \mathrm{g}$ of dry wt.

\section{CONCLUSION}

The presently selected HPTLC is validated and most accurate for the quantification and identification of lupeol in medicinally important grass $H$. contortus. The developed method has been found to be sensitive, accurate, precise, specific, and robust for the screening and quantification of sterols. Although, HPTLC has a few limitations like limited developing distance and lower plate efficiency in comparison to HPLC and gas chromatography. HPTLC is still an effective tool for quality evaluation of medicinal plants due to its simplicity, low cost, and low requirements. Thus, leaves of the species which are rich in lupeol can be used in pharmaceutical industry.

\section{ACKNOWLEDGMENT}

The authors would like to express their profound gratitude and sincere appreciation to UGC-BSR Single Girl Child Fellowship (Award letter no. and dated. F7-152/2007 BSR; 16-12-2013) and DBT-IPLS project (Project no. BT/PR-4548/INF/22/146/2012) sanctioned to Navjot Kaur, Punjabi University, Patiala, for using the facilities and financial supportofthisstudy. Theauthorsarealso thankful to Head, Department of Botany, Punjabi University, Patiala.

Table 3: Quantification of lupeol from different plant parts of H. contortus

\begin{tabular}{lll}
\hline Plant parts & Sample codes & $\begin{array}{l}\text { Amount of lupeol in } \\
\text { plant sample }(\% \mathbf{w} / \mathbf{w})\end{array}$ \\
\hline Leaves & HCLM & $10 \pm 0.13$ \\
Stem & HCSM & ND \\
Inflorescence & HCIM & ND \\
\hline
\end{tabular}

ND means not detected. H. contortus: Heteropogon contortus

Table 2: Recovery study of lupeol by the proposed HPTLC method

\begin{tabular}{|c|c|c|c|c|c|c|}
\hline Marker compound & $\begin{array}{l}\text { Amount present } \\
\text { in sample }(\mu \mathrm{g})\end{array}$ & Amount added $(\mu \mathrm{g})$ & $\begin{array}{l}\text { Theoretical } \\
\text { amount }(\mu \mathrm{g})\end{array}$ & Amount found $(\mu \mathrm{g})$ & Recovery (\%) & $\begin{array}{l}\text { Average } \\
\text { recovery (\%) }\end{array}$ \\
\hline \multirow{3}{*}{ Lupeol } & 100 & 75 & 175 & 172.62 & 98.64 & \multirow{3}{*}{99.05} \\
\hline & 100 & 100 & 200 & 198.46 & 99.23 & \\
\hline & 100 & 125 & 225 & 223.41 & 99.29 & \\
\hline
\end{tabular}

HPTLC: High-performance thin-layer chromatography 


\section{REFERENCES}

1. Aparna S, Amit S. Phytochemical and antimicrobial studies of medicinal plant Piperlongum Linn. Int J Pharmacogn Phytochem Res 2014;6:213-22.

2. Moreau RA, Whitaker BD, Hicks KB. Phytosterols, phytostanols, and their conjugates in foods: Structural diversity, quantitative analysis, and health-promoting uses. Prog Lipid Res 2002;41(6):457-500.

3. Chaturvedi PK, Bhui K, Shukla Y. Lupeol: Connotations for chemoprevention. Cancer Lett 2008;263(1):1-13

4. Saleem M, Alam A, Arifin S, Shah MS, Ahmed B, Sultana S. Lupeol, a triterpene, inhibits early responses of tumor promotion induced by benzoyl peroxide in murine skin. Pharmacol Res 2001;43(2):127-34.

5. Nigam N, Prasad S, George J, Shukla Y. Lupeol induces p53 and cyclin-B-mediated $\mathrm{G} 2 / \mathrm{M}$ arrest and targets apoptosis through activation of caspase in mouse skin. Biochem Biophys Res Commun 2009;381(2):253-8.

6. Margareth BC, Miranda JS. Biologicalactivities of Lupeol. Int J Biomed Pharmaceut Sci 2009;3:46-66.

7. Siddique HR, Saleem M. Beneficial health effects of lupeol triterpene: A review of preclinical studies. Life Sci 2011;88(7-8):285-93.

8. Saleem M. Lupeol, a novel anti-inflammatory and anti-cancer dietary triterpene. Cancer Lett 2009;285(2):109-15.

9. Geetha T, Varalakshmi P. Anti-inflammatory activity of lupeol and lupeol linoleate in rats. J Ethnopharmacol 2001;76(1):77-80.

10. Sunitha S, Nagaraj M, Varalakshmi P. Hepatoprotective effect of lupeol and lupeol linoleate on tissue antioxidant defence system in cadmiuminduced hepatotoxicity in rats. Fitoterapia 2001;72(5):516-23.

11. Blake JD, Richards GN. Polysaccharides of tropical pasture herbage-I, Studies on the distribution of the major polysaccharide components of spear grass (Heteropogoncontortus) during growth. Aust J Chem 1970;23:2353-60.

12. Beveridce RJ, Dekker RF, Richards GN, Tows M. Identification of myo-isositol, galactikol, and rbffixose in spear grass (Heteropogoncontortus).Aust J Chem 1972;25:677-8.

13. Chopra RN, Nayar SL, Chopra IC. Glossary of Indian Medicinal Plants. New Delhi, India: Council of Scientific and Industrial Research; 1956. p. 259-61.

14. Kirtikar KR, Basu BD. Indian Medicinal Plants. Vol. 2. Deharadun, India: International Book Distributors; 1935. p. 1074-6.

15. Ghante MH, Bhusari KP, Duragkar NJ. Evaluation of Heteropogoncontortus (L.) Beauv. methanolic extract for mast cell, cell membrane and free radical stabilization. Indo Am Pharmaceut Res 2012;2:1015-26.

16. Ghante MH, Bhusari KP, Duragkar NJ. Bronchorelaxent and antiinflammatory effect of Heteropogoncontortus (L.) Beauv. methanolic extract. Int J Pharm Tech Res 2013;5:99-104.

17. Sivagurunathan SK, Krishnamoorthy G. Comparative study on highperformance thin layer chromatography profileand antimicrobial activity of ethanolic and hydroalcoholic extract of Vetiveria zizanioides L. Root. Asian J Pharm Clin Res 2017;10:336-9.

18. Kumari K, Saggoo MI. Cytomorphology of some medicinal grasses from hangrang valley of district Kinnaur, Himachal Pradesh. Int J Pharm PharmSci 2016;8:187-90.

19. Hepsibah AH, Jothi GJ. A comparative study on the effect of solvents on the phytochemical profile and biological potential of Ormocarpum cochinchinenseAuct. Non (Lour.) Merrill. Int J Pharm PharmSci 2017;9:67-72.

20. ICH, Q2A. Text on validation of analytical procedures, In: Proceedings of the International Conference on Harmonization of Technical Requirements for Registration of Pharmaceuticals for Human Use. Geneva: ICH, Q2A; 1994.

21. Ariburnu E, Uludag MF, Yalcinkaya H, Yesilada E. Comparative determination of sibutramine as an adulterant in natural slimming products by HPLC and HPTLC densitometry. J Pharm Biomed Anal 2012;64-65:77-81. 